\title{
La Seguridad en la Producción de Alimentos en la Granja: Buenas Prácticas Agrícolas y Buenas Prácticas de Manejo - Sanidad en el Campo ${ }^{1}$
}

\author{
Federico G. Caro, Alexandra Chang, Renée Goodrich-Schneider, y Keith R. Schneider ${ }^{2}$
}

\section{Introducción}

Las Buenas Prácticas Agrícolas (BPA) y Buenas Prácticas de Manejo (BPM) abarcan los procedimientos generales que los productores, empacadores y procesadores de frutas y verduras frescas deben seguir para garantizar la seguridad de sus productos. Las BPA son usadas antes de la cosecha (es decir, en el campo), mientras que las BPM se utilizan después de la cosecha, incluyendo el empaque y envío. Esta hoja informativa cubre las prácticas de cosecha relacionadas con la sanidad en el campo. Hay otras siete hojas informativas del Servicio de Extensión de Florida acerca de la "Inocuidad de los Alimentos en la Granja." Esta serie se centra en aspectos específicos del programa de BPA y cómo se relacionan con los cultivos y las prácticas de la Florida.

\section{Los Riesgos Microbianos}

Los productos frescos se pueden contaminar con microorganismos patógenos antes, durante y después de la cosecha. Fuentes de riesgos de contaminación microbiana en el campo incluyen el suelo, los fertilizantes, el agua, los trabajadores, y el equipo. La limpieza y mantenimiento inadecuado de los equipos y prácticas insalubres de cosecha son ejemplos de mala higiene en el campo que pueden aumentar el riesgo de contaminación de dichos productos.

\section{Cómo Controlar Posibles Riesgos}

En respuesta y reconocimiento de los crecientes problemas de seguridad alimentaria, la Ley de Modernización Para la Inocuidad de los Alimentos fue aprobada por el Congreso y firmada por el Presidente en Enero del 2011. La nueva ley exige a las empresas implementar un programa de seguridad en la producción de alimentos que minimice significativamente los riesgos asociados a las enfermedades transmitidas por alimentos contaminados. Tomar medidas inmediatas para aplicar buenas prácticas agrícolas de saneamiento en el campo beneficia a las empresas y aumenta la seguridad de los productos en general.

Las Buenas Prácticas Agrícolas son fundamentales para garantizar la seguridad y la calidad de los productos frescos. El estatuto 21 del Código de Regulaciones Federales, Parte 110, sección 20 describe BPA para manejar las instalaciones, equipos y plantas en el área de producción. Incluye también los requisitos para el almacenamiento adecuado de equipos y el control de plagas (1). La Administración de Alimentos y Fármacos de EE.UU. (FDA) identificaron las siguientes deficiencias que deben ser consideradas durante la recolección y el mantenimiento de los equipos (2).

1. The English version of this document is FSHN10-12s/FS189 Food Safety on the Farm: Good Agricultural Practices and Good Handling Practices - Field Sanitation. Este documento es FSHN10-12s, uno de una serie del Departamento de Ciencia de los Alimentos y Nutrición Humana, Servicio de Extensión Cooperativa, IFAS de la Universidad de Florida. Publicación: febrero de 2013. Ciencia de los Alimentos y Nutrición Humana, Servicio de Extensión Cooperativa, IFAS de la Universidad de Florida, Gainesville, FL 32611-0370. Por favor, visite nuestro sitio web EDIS en http://edis.ifas.ufl.edu/.

2. F. G. Caro, BS., técnico; A. Chang, estudiante de posgrado; R. M. Goodrich-Schneider, PhD, profesora asociada, y K. R. Schneider, PhD, profesor asociado; todos del Depto. de Ciencia de los Alimentos y Nutrición Humana, Servicio de Extensión Cooperativa, IFAS de la Universidad de Florida, Gainesville, FL 32611-0370.

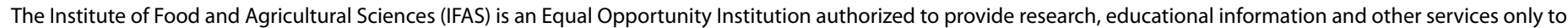

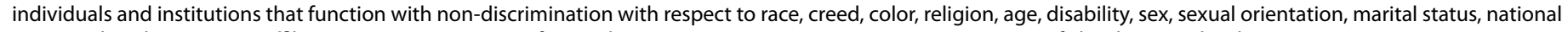
origin, political opinions or affiliations. U.S. Department of Agriculture, Cooperative Extension Service, University of Florida, IFAS, Florida A\&M University Cooperative Extension Program, and Boards of County Commissioners Cooperating. Nick T. Place, Dean 


\section{Consideraciones Gererales durante la Cosecha}

- Limpiar y desinfectar las instalaciones de almacenamiento de los contenedores de productos cosechado antes de su uso.

- Inspeccionar las instalaciones buscando evidencia de plagas como roedores, aves e insectos.

- Limpiar y desinfectar los contenedores reutilizables antes de usarlos para transportar frutas y vegetales frescos.

- Deseche los recipientes utilizados para almacenar los productos si están dañados o si no se pueden limpiar a fondo.

- Tenga cuidado de no contaminar los productos frescos que se laven, refrigeren y empaquen en el campo. El contacto con cualquier fuente de patógenos como el estiércol o desechos biológicos sólidos, agua contaminada, trabajadores con falta de higiene, contenedores y cajas sucias pueden contaminar los productos frescos en el proceso de lavado, refrigeración o empaque.

- Elimine la mayor cantidad de polvo y lodo posible en la cosecha. Cuando la eliminación del lodo en el campo no es práctico, entonces el lodo debe ser retirado en las instalaciones de embalaje antes de la clasificación, control de calidad y empaque.

\section{Manteninmiento de Equipos y Herraminetas}

Todo equipo de campo como las cosechadoras, cuchillos, recipientes, mesas, cestas, materiales de empaque, cepillos, cubos, etc., puede ser una fuente de patógenos. La limpieza frecuente y el mantenimiento de estos equipos pueden ayudar a prevenir la contaminación de los productos frescos. Las siguientes sugerencias deben ser consideradas.

- Utilizar equipos de cosecha y empaque de manera adecuada y mantenerlos limpios. Los equipos utilizados para transportar basura o estiércol deben ser limpiados y desinfectados profundamente antes de entrar en contacto con productos frescos.

- Mantenga los recipientes utilizados en la cosecha limpios para evitar la contaminación cruzada de los productos frescos. Cuando se utilicen en varias ocasiones durante una misma cosecha, se deben limpiar después de cada descarga antes de reutilizarlos. Los contenedores que se encuentren afuera deben ser limpiados antes de su uso.
- Asignar la responsabilidad del mantenimiento a la persona encargada de la gestión de equipos. La persona a cargo debe conocer cómo está siendo utilizado el equipo, asegurar que el equipo está funcionando correctamente, y vigilar que el equipo se limpie y desinfecte regularmente.

\section{Referencias}

1. Código de Regulaciones Federales. 2010. Buenas Prácticas de Manufactura en la fabricación, empaque o almacenamiento de alimentos humanos: las plantas y jardines. Título 21, Parte 110.20. Washington, DC: EE.UU. Administración de Alimentos y Fármacos de la Oficina del Registro Federal.

2. Administración de Alimentos y Fármacos (FDA). 1998. Guía para Reducir al Mínimo el Riesgo Microbiano en Frutas y Verduras Frescas. Washington, DC: EE.UU. El Departamento de Salud y Servicios Humanos, la FDA. Disponible en: http://www.fda.gov/downloads/Food/ GuidanceComplianceRegulatoryInformation/GuidanceDocuments/ProduceandPlanProducts/UCM169112. pdf. Consultado el 13 de Marzo, 2011. 